\title{
O OPEN ACCESS
}

\section{Extent and selectivity of sexual orientation disclosure and its association with HIV and other STI testing patterns among gay, bisexual and other men who have sex with men}

\author{
Rayner Kay Jin Tan, ${ }^{\oplus}$ Alvin Kuo Jing Teo, ${ }^{\circ}$ Nashwinder Kaur, ${ }^{2}$ \\ Jack Harrison-Quintana, ${ }^{3}$ Chen Seong Wong, ${ }^{2}$ Mark I-Cheng Chen ${ }^{\oplus 1,2}$
}

\begin{abstract}
- Additional material is published online only. To view please visit the journal online (http://dx.doi.org/10.1136/ sextrans-2018-053866).

${ }^{1}$ Saw Swee Hock School of Public Health, National University of Singapore, Singapore, Singapore ${ }^{2}$ National Centre for Infectious Diseases, Singapore, Singapore ${ }^{3}$ Grindr for Equality, Grindr LLC, Los Angeles, California, USA
\end{abstract}

\section{Correspondence to}

Rayner Kay Jin Tan, Saw Swee Hock School of Public Health, National University Singapore, Singapore 117549, Singapore; rayner.tan@u.nus.edu

Received 4 October 2018 Revised 14 January 2019 Accepted 16 February 2019 Published Online First 27 March 2019

\section{Check for updates}

(c) Author(s) (or their employer(s)) 2019. Re-use permitted under CC BY-NC. No commercial re-use. See rights and permissions. Published by BMJ.

To cite: Tan RKJ,

Teo AKJ, Kaur N, et al.

Sex Transm Infect

2019:95:273-278

\begin{abstract}
Objectives Gay, bisexual and other men who have sex with men (GBMSM) in Singapore may fear disclosing their sexual orientation to others due to negative societal attitudes, and the law that criminalises sexual relations between men, which may, in turn, impede access to HIV/sexually transmitted infection (STI)-related health services. This study attempts to determine how selective disclosure to varying social groups, and the extent of disclosure, may serve to impact HIV/STI testing patterns among GBMSM.
\end{abstract}

Methods In this observational study, we recruited GBMSM in Singapore through an online cross-sectional survey disseminated via the smartphone app Grindr from 14 January to 11 February 2018. Respondents provided information on their sociodemographic characteristics, disclosure of sexual orientation towards other lesbian, gay, bisexual, transgender and questioning (LGBTQ) individuals, non-LGBTQ family members, non-LGBTQ friends and non-LGBTQ colleagues, along with their HIV/ STI testing patterns. Extent of disclosure was defined as the number of social groups that a participant had disclosed his sexual orientation to. Statistical analyses were conducted through descriptive statistics, multivariable binary, ordinal, and multinomial logistic regression models.

Results We recruited 1339 respondents, of which 1098 who had provided their response to questions on HIV/STI testing were included in the analytic sample. Multivariable analyses indicated that disclosure towards non-LGBTQ family members (adjusted OR [aOR] 1.85, $95 \% \mathrm{Cl} 1.12$ to 3.07 ) and other LGBTQ individuals (aOR $1.63,95 \% \mathrm{Cl} 1.12$ to 2.37 ) were positively associated with recent HIV testing, whereas disclosure towards non-LGBTQ colleagues (aOR 1.56, 95\% Cl 1.09 to 2.22) was positively associated with regular HIV testing. Extent of disclosure exhibited a positive, dose-response relationship with all testing outcomes.

Conclusions Results indicate how the fear of being identified as an LGBTQ individual may deter GBMSM from getting tested for HIV and other STIs. Health services should bridge the gaps to accessing healthcare among individuals who fear being stigmatised for attending sexual health-specific clinics or being identified as GBMSM.

\section{Key messages}

- Gay, bisexual and other men who have sex with men (GBMSM) in Singapore may fear disclosing their sexual orientation to others due to negative societal attitudes and criminalisation of sex between men.

- We assessed how sexual orientation disclosure to non-lesbian, gay, bisexual, transgender and questioning (LGBTQ) family members, friends, colleagues or other LGBTQ individuals may impact HIV/sexually transmitted infection (STI) testing among GBMSM.

- Sexual orientation disclosure to other LGBTQ individuals was associated with recent HIV testing, possibly highlighting the efficacy of community-based services.

- Extent of sexual orientation disclosure exhibited a positive, dose-response relationship with all measures of HIV and other STI testing.

\section{INTRODUCTION}

Gay, bisexual and other men who have sex with men (GBMSM) are a key population that is disproportionately affected by HIV, with concentrated epidemics that continue to expand in communities of GBMSM across the world. ${ }^{1}$ Early detection of HIV acquisition among GBMSM is crucial in the global fight against HIV, as the knowledge of one's own HIV status has been linked to the reduction of sexual risk behaviours. ${ }^{2-4}$ Early initiation of antiretroviral therapy following diagnosis has also been shown to reduce onward HIV transmission in virally suppressed individuals and leads to improved survival for individuals living with $\mathrm{HIV}^{56}$

Factors associated with HIV testing among GBMSM have been well established in the literature. Demographic factors such as increasing age and educational attainment are positively associated, ${ }^{78}$ whereas the lack of HIV knowledge and low HIV risk perception are negatively associated with previous and recent HIV testing. ${ }^{9} 10$ Sexual identity is an important factor that is associated with HIV testing among GBMSM, with those who identify as 
gay being more likely to had ever tested for HIV, relative to those who identify as bisexual or straight. ${ }^{78}$

As at end of 2017, 7982 Singapore residents had been notified to Singapore's Ministry of Health $(\mathrm{MOH})$ to be infected with HIV, of whom 6022 remain alive. In 2017, a total of 434 incident cases of HIV were reported, of which $60.4 \%$ were attributed to same-sex sexual transmission, and only $33.0 \%$ of these cases were diagnosed through voluntary HIV screening. ${ }^{11}$ Despite the increasing burden of HIV in the local GBMSM community, few studies have been conducted and published on this issue in Singapore, and this may be attributable to negative societal attitudes towards GBMSM among the general population, ${ }^{12}$ and Section $377 \mathrm{~A}$ of the Singapore penal code, which criminalises sexual relations between men with imprisonment for a term not exceeding 2 years.

HIV testing in Singapore is available at government-run and private healthcare providers, alongside a list of 10 'anonymous testing sites' based in nine general practitioner (GP) clinics and at one local non-governmental organisation (NGO). Under the Infectious Diseases Act in Singapore, all individuals who test positive for HIV must, by law, be notified to the $\mathrm{MOH}$ within 72 hours of diagnosis. The $\mathrm{MOH}$ introduced the anonymous HIV testing scheme in 1991 to encourage HIV testing among individuals who might otherwise be hesitant of registering for the test with their personal identifiers. Under this scheme, no personal identifiers are collected at the clinic. ${ }^{13}$

Sexual orientation disclosure refers to the intentional disclosure of an individual's sexual orientation to other individuals, or groups of individuals; the decision to disclose one's sexual orientation may be driven by factors that vary for varying social groups such as family members, colleagues or co-workers, friends and healthcare providers. ${ }^{14-16}$ Notwithstanding several studies that have found evidence for a positive association between measures of sexual orientation disclosure and HIV testing behaviours among GBMSM, ${ }^{17} 18$ two gaps in the extant literature remain noteworthy. First, past studies have largely focused on sexual orientation disclosure to healthcare professionals, or as a singular construct of 'outness', a colloquial term to indicate the extent of sexual orientation disclosure, and their impact on HIV testing, but have not investigated how selective disclosure to varying social groups may impact the uptake of testing for both HIV and other sexually transmitted infections (STIs). Second, to our knowledge, there is no published research on the public health dimensions of sexual orientation disclosure in South-East Asia, and specifically, Singapore, where the sociolegal cost of disclosure is arguably high. This study thus attempts to determine how selective disclosure to varying social groups, and the extent of disclosure, may serve to impact HIV/STI testing patterns among GBMSM in Singapore.

\section{METHODS}

A web-based survey was developed and hosted on SurveyMonkey (SurveyMonkey, San Mateo, CA, USA), and subsequently disseminated by Grindr, a popular geosocial networking app among GBMSM in the present setting. This observational, cross-sectional survey sought to recruit a sample of Grindr-using GBMSM, who were at least 18 years old, and were residing in Singapore at the point of the survey. Ethics approval was obtained from the institutional review board at the National University of Singapore (NUS-IRB Reference Code S-17-335) prior to data collection.

From 14 January 14 to 11 February 2018, all Grindr users in Singapore were invited to participate in the survey through a pop-up text box that app users received two times per week on opening the app. The language of the advertisement alternated between English and one of Singapore's three other official languages: Mandarin, Bahasa Melayu (Malay) and Tamil. On accepting the invitation to participate, Grindr users were redirected to the SurveyMonkey page with a link to the participant information sheet and gave consent to participate by clicking a button. Participants could choose to complete the survey in one of four languages: English, Mandarin, Bahasa Melayu (Malay) or Tamil. The average time taken to complete the survey was about 2 min. Multiple responses from the same device were not allowed to prevent duplicate entries from respondents.

The survey collected sociodemographic information from respondents, including residence status, age, ethnicity and educational attainment. Respondents were asked if they had disclosed their sexual orientation to non-lesbian, gay, bisexual, transgender and questioning (LGBTQ) family members, non-LGBTQ friends, non-LGBTQ colleagues and other LGBTQ individuals. A categorical, ordinal variable on the extent of sexual orientation disclosure was constructed based on the number of groups that a respondent had disclosed his sexual orientation to. Regarding HIV/STI testing, respondents were asked to self-report their HIV status, when they had their last voluntary HIV test, how often they test voluntarily for HIV, and for other STIs, and the location of their last voluntary HIV test. Recent and nonrecent HIV testing were defined as having had a voluntary HIV test in the last 12 months and more than 12 months ago, respectively; regular testing was defined as voluntary testing for HIV or other STIs at least once a year. Participants were asked about their voluntary HIV testing histories, as there are several circumstances in which HIV tests are mandated in Singapore, such as prior to compulsory military service for Singapore men aged 18 years, ${ }^{18} 19$ and for foreign nationals seeking employment and education in Singapore. ${ }^{20}$

Statistical analysis was carried out using the statistical software STATA V.15 (Stata Corp, College Station, TX, USA). We employed descriptive statistics to elucidate trends in sample characteristics, whereas binary logistic regression models were used to compute the crude OR and adjusted OR (aOR) for frequency of HIV and other STI testing. Multinomial logistic regression was employed to examine the association between respondents' sociodemographic attributes and disclosure of sexual orientation with the respondents' recency and location of their last HIV test. Both binary and ordinal logistic regression models were employed to investigate the association between sociodemographic characteristics and measures of sexual orientation disclosure. Statistical significance was set at $\mathrm{p}<0.05$.

\section{RESULTS}

\section{Sociodemographic attributes and HIV/STI testing patterns of analytic sample}

Of 1339 responses, 10 were ineligible due to their age, 167 respondents quit the survey right after indicating the language they preferred to take the survey in, and 64 respondents dropped out prior to completing the questions on HIV/STI testing, leaving 1098 in the analytic sample, and a survey completion rate of $82.0 \%$. Of the 1098 respondents, $63.5 \%$ $(n=697)$ reported having disclosed their sexual orientation to other LGBTQ individuals, 55.1\% $(\mathrm{n}=605)$ to non-LGBTQ friends, $30.2 \%(\mathrm{n}=331)$ to non-LGBTQ family members and $28.6 \%(n=314)$ to non-LGBTQ colleagues (table 1). Regarding self-reported HIV status, $6.6 \%(n=73)$ of respondents identified as being HIV positive, $74.8 \%(\mathrm{n}=821)$ as HIV 
Table 1 Sample description by sociodemographic attributes and HIV/ STI testing patterns $(n=1098)$

\begin{tabular}{|c|c|c|}
\hline Demographic variables & $\mathrm{n}$ & $\%$ \\
\hline \multicolumn{3}{|l|}{ Age (years) } \\
\hline $18-29$ & 449 & 40.9 \\
\hline $30-39$ & 385 & 35.1 \\
\hline $40-49$ & 169 & 15.4 \\
\hline 50 years and above & 95 & 8.7 \\
\hline \multicolumn{3}{|l|}{ Residence status } \\
\hline Singapore citizen or permanent resident & 797 & 72.6 \\
\hline Nonresidents & 301 & 27.4 \\
\hline \multicolumn{3}{|l|}{ Educational attainment } \\
\hline Secondary and below & 124 & 11.3 \\
\hline Pre-university & 308 & 28.1 \\
\hline Bachelor's degree & 478 & 43.5 \\
\hline Postgraduate degree & 188 & 17.1 \\
\hline \multicolumn{3}{|l|}{ Disclosure of sexual orientation } \\
\hline Non-LGBTQ family & 331 & 30.2 \\
\hline Non-LGBTQ friends & 605 & 55.1 \\
\hline Non-LGBTQ colleagues & 314 & 28.6 \\
\hline Other LGBTQ individuals & 697 & 63.5 \\
\hline \multicolumn{3}{|l|}{ Extent of sexual orientation disclosure } \\
\hline Never disclosed to anyone & 187 & 17.0 \\
\hline Disclosed to one group & 378 & 34.4 \\
\hline Disclosed to two groups & 190 & 17.3 \\
\hline Disclosed to three groups & 183 & 16.7 \\
\hline Disclosed to four groups & 160 & 14.6 \\
\hline \multicolumn{3}{|l|}{ HIV status } \\
\hline HIV positive & 73 & 6.6 \\
\hline HIV negative & 821 & 74.8 \\
\hline Don't know & 204 & 18.6 \\
\hline \multicolumn{3}{|l|}{ When did you go for your last voluntary HIV test? $(n=1025)^{*}$} \\
\hline In the last 6 months & 517 & 50.4 \\
\hline $6-12$ months ago & 163 & 15.9 \\
\hline More than a year ago & 175 & 17.1 \\
\hline Never tested voluntarily for HIV & 170 & 16.6 \\
\hline \multicolumn{3}{|l|}{ Where did you go for your last voluntary HIV test? $(n=855) \dagger$} \\
\hline Government-run clinic or hospital & 164 & 19.2 \\
\hline Privately run clinic or hospital & 237 & 27.7 \\
\hline Anonymous testing site (general practitioner) & 115 & 13.5 \\
\hline Anonymous testing site (non-governmental organisation) & 240 & 28.1 \\
\hline Overseas & 84 & 9.8 \\
\hline Others $\ddagger$ & 15 & 1.8 \\
\hline \multicolumn{3}{|l|}{ How often do you test voluntarily for HIV? $(n=1025)^{*}$} \\
\hline Once a month & 9 & 0.9 \\
\hline Once every 3 months & 123 & 12.0 \\
\hline Once every 6 months & 195 & 19.0 \\
\hline Once a year & 251 & 24.5 \\
\hline Once every few years & 95 & 9.3 \\
\hline I don't test regularly / never tested & 352 & 34.3 \\
\hline \multicolumn{3}{|l|}{ How often do you test voluntarily for other STI? ( $n=1098)$} \\
\hline Once a month & 10 & 0.9 \\
\hline Once every 3 months & 56 & 5.1 \\
\hline Once every 6 months & 163 & 14.9 \\
\hline Once a year & 257 & 23.4 \\
\hline Once every few years & 89 & 8.1 \\
\hline I don't test regularly / never tested & 521 & 47.5 \\
\hline
\end{tabular}

*Excludes 73 HIV-positive respondents.

tExcludes 73 HIV-positive respondents and 170 respondents who had never tested for HIV. ¥All open-ended responses accompanying this response indicated 'self-testing' for HIV. LGBTQ, lesbian, gay, bisexual, transgender and questioning; STI, sexually transmitted infection. negative and $18.6 \%(n=204)$ reported being unaware of their HIV status.

Of the 1025 respondents who self-reported as not being HIV positive, $66.3 \%(n=680)$ had a recent HIV test in the last 12 months, $17.1 \%(n=175)$ had a nonrecent HIV test and $16.6 \%$ $(\mathrm{n}=170)$ had never taken a voluntary HIV test. When asked about the regularity of their voluntary tests for HIV and other STIs, 67.6\% $(\mathrm{n}=578)$ and $56.8 \%(\mathrm{n}=486)$ reported regularly testing for HIV and other STIs, respectively. Of the 855 respondents who reported ever having had a voluntary HIV test, 28.1\% $(n=240)$ had their last test at the NGO-based anonymous testing site, $27.7 \%(\mathrm{n}=237)$ at a privately run clinic or hospital, $19.2 \%$ $(\mathrm{n}=164)$ at a government-run clinic or hospital, 13.5\% $(\mathrm{n}=115)$ at a GP-based anonymous testing site, and 11.6\% $(\mathrm{n}=99)$ overseas or through self-testing kits.

\section{Factors associated with recency of HIV testing}

On multivariable multinomial logistic regression (table 2), several factors were significantly associated with an increased likelihood of being a nonrecent over being a never HIV tester: ages $30-39$ years $(\mathrm{aOR}=2.93,95 \%$ CI 1.70 to 5.06$), 40-49$ years $(\mathrm{aOR}=9.28,95 \%$ CI 3.95 to 21.82$)$ and 50 years and above $(\mathrm{aOR}=2.27,95 \%$ CI 1.03 to 4.99$)$ relative to $18-29$ years; and having a bachelor's $(\mathrm{aOR}=3.10,95 \% \mathrm{CI} 1.51$ to 6.37$)$ or postgraduate degree $(\mathrm{aOR}=3.08,95 \% \mathrm{CI} 1.25$ to 7.61$)$ relative to those with secondary education and below.

As for being recent rather than never HIV testers, significant positive associations were as follows: ages 30-39 years $(\mathrm{aOR}=2.22,95 \% \mathrm{CI} 1.42$ to 3.45$)$ and $40-49$ years $(\mathrm{aOR}=4.99$, $95 \%$ CI 2.28 to 10.89 ) relative to $18-29$ years; and having a pre-university education $(\mathrm{aOR}=2.14,95 \% \mathrm{CI} 1.25$ to 3.67$)$, bachelor's degree ( $\mathrm{aOR}=3.82,95 \% \mathrm{CI} 2.22$ to 6.57$)$ and postgraduate degree $(\mathrm{aOR}=4.65,95 \%$ CI 2.25 to 9.58 ) relative to those with secondary education and below. Non-Singapore residents $(\mathrm{aOR}=2.29$, 95\% CI 1.46 to 3.61$)$, as well as those who had ever disclosed their sexual orientation to non-LGBTQ family members $(\mathrm{aOR}=1.85,95 \% \mathrm{CI} 1.12$ to 3.07$)$ and other LGBTQ individuals ( $\mathrm{aOR}=1.63,95 \% \mathrm{CI} 1.12$ to 2.37 ), also had a greater likelihood of being recent HIV testers.

\section{Factors associated with regularity of HIV and STI testing}

On multivariable binary logistic regression, those aged 30-39 years $(\mathrm{aOR}=1.70,95 \% \mathrm{CI} 1.25$ to 2.30$)$ and $40-49$ years (aOR $=1.85,95 \%$ CI 1.23 to 2.78 ) were more likely than those aged 18-29 years to be regular HIV testers (table 3). Those who had a bachelor's ( $\mathrm{aOR}=1.73,95 \% \mathrm{CI} 1.11$ to 2.69 ) or postgraduate degrees $(\mathrm{aOR}=2.01,95 \% \mathrm{CI} 1.21$ to 3.35$)$ were more likely than those with secondary school education and below to be regular HIV testers. Nonresidents $(\mathrm{aOR}=1.51,95 \% \mathrm{CI}$ 1.12 to 2.04 ) were more likely than Singaporean residents while those who had disclosed their sexual orientation to non-LGBTQ colleagues ( $\mathrm{aOR}=1.56,95 \% \mathrm{CI} 1.09$ to 2.22 ) were more likely than those who had not to be regular HIV testers.

Respondents aged $30-39$ years $(\mathrm{aOR}=1.39$, 95\% CI 1.04 to 1.86), 40-49 years $(\mathrm{aOR}=1.60,95 \% \mathrm{CI} 1.10$ to 2.32$)$ and 50 years and above $(\mathrm{aOR}=1.66,95 \% \mathrm{CI} 1.05$ to 2.63$)$ were more likely than those who were 18-29 years to be regular testers for other STIs. Those with a postgraduate degree $(\mathrm{aOR}=1.63,95 \%$ CI 1.01 to 2.64) were more likely than those with secondary school education and below, and nonresidents $(\mathrm{aOR}=1.50,95 \%$ CI 1.14 to 1.99 ) were also more likely than Singapore residents to be regular testers for other STIs. 
Table 2 Multivariable multinomial logistic regression with aORs $(95 \% \mathrm{Cl})$ for recency of last voluntary HIV test $(\mathrm{n}=1025)$

\begin{tabular}{|c|c|c|c|c|c|c|}
\hline & \multicolumn{3}{|c|}{$\begin{array}{l}\text { Nonrecent HIV test } \\
\text { (more than } 12 \text { months ago; } n=175 \text { ) }\end{array}$} & \multicolumn{3}{|c|}{$\begin{array}{l}\text { Recent HIV test } \\
\text { (within last } 12 \text { months; } n=680 \text { ) }\end{array}$} \\
\hline & aOR & $95 \% \mathrm{Cl}$ & $P$ value & $\mathrm{aOR}$ & $95 \% \mathrm{Cl}$ & $P$ value \\
\hline \multicolumn{7}{|l|}{ Age (ref=18-29 years) } \\
\hline $30-39$ & 2.93 & 1.70 to 5.06 & $<0.001$ & 2.22 & 1.42 to 3.45 & $<0.001$ \\
\hline $40-49$ & 9.28 & 3.95 to 21.82 & $<0.001$ & 4.99 & 2.28 to 10.89 & $<0.001$ \\
\hline 50 years and above & 2.27 & 1.03 to 4.99 & 0.041 & 1.52 & 0.79 to 2.90 & 0.206 \\
\hline \multicolumn{7}{|c|}{ Education level (ref=secondary and below) } \\
\hline Pre-university & 1.99 & 0.96 to 4.12 & 0.063 & 2.14 & 1.25 to 3.67 & 0.006 \\
\hline Bachelor's degree & 3.10 & 1.51 to 6.37 & 0.002 & 3.82 & 2.22 to 6.57 & $<0.001$ \\
\hline Postgraduate degree & 3.08 & 1.25 to 7.61 & 0.015 & 4.65 & 2.25 to 9.58 & $<0.001$ \\
\hline $\begin{array}{l}\text { Non-Singaporean citizen or } \\
\text { permanent resident }\end{array}$ & 1.56 & 0.89 to 2.72 & 0.122 & 2.29 & 1.46 to 3.61 & $<0.001$ \\
\hline \multicolumn{7}{|c|}{ Disclosure of sexual orientation } \\
\hline Non-LGBTQ family & 1.63 & 0.90 to 2.96 & 0.105 & 1.85 & 1.12 to 3.07 & 0.017 \\
\hline Non-LGBTQ friends & 1.48 & 0.88 to 2.49 & 0.140 & 1.21 & 0.80 to 1.85 & 0.370 \\
\hline Non-LGBTQ colleagues & 1.39 & 0.73 to 2.66 & 0.313 & 1.46 & 0.85 to 2.50 & 0.175 \\
\hline Other LGBTQ individuals & 1.05 & 0.66 to 1.68 & 0.836 & 1.63 & 1.12 to 2.37 & 0.011 \\
\hline
\end{tabular}

Reference outcome category: never tested for HIV ( $n=170)$.

LGBTQ, lesbian, gay, bisexual, transgender and questioning; aOR, adjusted OR.

\section{Extent of sexual orientation disclosure and HIV/STI testing patterns}

Table 4 summarises the multinomial and binary logistic regression models estimating the aOR of the extent of sexual orientation disclosure on the recency of HIV, and regularity of HIV and other STI tests in the analytic sample, respectively. We observed a strong, positive, dose-response relationship between the extent of sexual orientation disclosure and all HIV and other STI testing outcomes.

\section{Factors associated with location of last voluntary HIV test}

Several factors were significantly associated with an increased likelihood of being tested at sites other than government-run clinics and hospitals (online supplementary table S1 and accompanying description). Differences by age and educational attainment were observed, with a notable finding being that those with bachelor's ( $\mathrm{aOR}=3.33,95 \%$ CI 1.16 to 9.55$)$ or postgraduate degrees $(\mathrm{aOR}=3.78,95 \% \mathrm{CI} 1.22$ to 11.74$)$ were more likely to have had their last voluntary HIV test overseas or through self-testing kits. However, no consistent associations between disclosure and site of last voluntary HIV test were observed.

\section{DISCUSSION}

GBMSM who were older and had higher educational attainment were more likely to had tested recently for HIV, and more frequently for HIV and other STIs. This is consistent with findings in the extant literature across different settings. ${ }^{7810}$ The relationship between HIV testing and age or educational attainment

Table 3 Multivariable binary logistic regression with crude and aORs ( $95 \%$ Cl) for being a regular tester for HIV ( $n=1025)$ and other STIs ( $n=1098$ )

\begin{tabular}{|c|c|c|c|c|c|c|c|c|c|c|c|c|}
\hline & \multicolumn{6}{|c|}{ Regular tester for HIV (at least once a year, $n=578$ ) } & \multicolumn{6}{|c|}{ Regular tester for other STIs (at least once a year, $n=486$ ) } \\
\hline & OR & $95 \% \mathrm{Cl}$ & $P$ value & $\mathrm{aOR}$ & $95 \% \mathrm{Cl}$ & $P$ value & OR & $95 \% \mathrm{Cl}$ & $P$ value & aOR & $95 \% \mathrm{Cl}$ & $P$ value \\
\hline \multicolumn{13}{|c|}{ Age (ref=18-29 years) } \\
\hline $30-39$ & 1.87 & 1.41 to 2.49 & $<0.001$ & 1.70 & 1.25 to 2.30 & 0.001 & 1.46 & 1.11 to 1.92 & 0.007 & 1.39 & 1.04 to 1.86 & 0.028 \\
\hline $40-49$ & 1.87 & 1.26 to 2.76 & 0.002 & 1.85 & 1.23 to 2.78 & 0.003 & 1.59 & 1.11 to 2.27 & 0.011 & 1.60 & 1.10 to 2.32 & 0.014 \\
\hline 50 years and above & 1.25 & 0.79 to 1.99 & 0.338 & 1.31 & 0.81 to 2.12 & 0.279 & 1.58 & 1.01 to 2.46 & 0.045 & 1.66 & 1.05 to 2.63 & 0.030 \\
\hline \multicolumn{13}{|c|}{ Education level (ref=secondary and below) } \\
\hline Pre-university & 1.34 & 0.86 to 2.08 & 0.193 & 1.42 & 0.9 to 2.25 & 0.134 & 1.19 & 0.77 to 1.83 & 0.428 & 1.29 & 0.83 to 2.01 & 0.259 \\
\hline Bachelor's degree & 1.93 & 1.27 to 2.94 & 0.002 & 1.73 & 1.11 to 2.69 & 0.015 & 1.39 & 0.92 to 2.08 & 0.115 & 1.35 & 0.89 to 2.06 & 0.159 \\
\hline Postgraduate degree & 2.56 & 1.57 to 4.16 & $<0.001$ & 2.01 & 1.21 to 3.35 & 0.007 & 1.85 & 1.16 to 2.93 & 0.009 & 1.63 & 1.01 to 2.64 & 0.046 \\
\hline $\begin{array}{l}\text { Non-Singaporean } \\
\text { citizen or } \\
\text { permanent resident }\end{array}$ & 1.37 & 1.04 to 1.81 & 0.028 & 1.51 & 1.12 to 2.04 & 0.008 & 1.39 & 1.06 to 1.81 & 0.016 & 1.50 & 1.14 to 1.99 & 0.004 \\
\hline \multicolumn{13}{|c|}{ Disclosure of sexual orientation } \\
\hline Non-LGBTQ family & 1.69 & 1.28 to 2.24 & $<0.001$ & 1.28 & 0.93 to 1.76 & 0.134 & 1.36 & 1.05 to 1.76 & 0.021 & 1.16 & 0.86 to 1.56 & 0.342 \\
\hline Non-LGBTQ friends & 1.34 & 1.05 to 1.72 & 0.020 & 1.00 & 0.73 to 1.35 & 0.979 & 1.10 & 0.86 to 1.39 & 0.448 & 0.90 & 0.67 to 1.21 & 0.492 \\
\hline $\begin{array}{l}\text { Non-LGBTQ } \\
\text { colleagues }\end{array}$ & 1.88 & 1.41 to 2.49 & $<0.001$ & 1.56 & 1.09 to 2.22 & 0.015 & 1.43 & 1.10 to 1.86 & 0.007 & 1.36 & 0.98 to 1.90 & 0.069 \\
\hline $\begin{array}{l}\text { Other LGBTQ } \\
\text { individuals }\end{array}$ & 1.48 & 1.15 to 1.91 & 0.003 & 1.29 & 0.98 to 1.7 & 0.074 & 1.20 & 0.94 to 1.54 & 0.147 & 1.13 & 0.87 to 1.47 & 0.372 \\
\hline
\end{tabular}

LGBTQ, lesbian, gay, bisexual, transgender and questioning; aOR, adjusted OR. 
Table 4 Summary of aORs $(95 \% \mathrm{CI})$ for recency of HIV and frequency of HIV/STI testing by extent of disclosure

\begin{tabular}{|c|c|c|c|c|c|c|c|c|c|c|c|c|}
\hline & \multicolumn{6}{|c|}{ Recency of HIV Test } & \multicolumn{6}{|c|}{ Frequency of HIV or other STI Test } \\
\hline & \multicolumn{3}{|c|}{$\begin{array}{l}\text { Nonrecent HIV test* } \\
\text { (more than } 12 \text { months ago) }\end{array}$} & \multicolumn{3}{|c|}{$\begin{array}{l}\text { Recent HIV test* } \\
\text { (within last } 12 \text { months) }\end{array}$} & \multicolumn{3}{|c|}{$\begin{array}{l}\text { Regular HIV test† (at least once a } \\
\text { year) }\end{array}$} & \multicolumn{3}{|c|}{$\begin{array}{l}\text { Regular test for other STI‡ (at leas } \\
\text { once a year) }\end{array}$} \\
\hline & $\mathrm{aOR}$ & $95 \% \mathrm{Cl}$ & $P$ value & $\mathrm{aOR}$ & $95 \% \mathrm{Cl}$ & $P$ value & $\mathrm{aOR}$ & $95 \% \mathrm{Cl}$ & $P$ value & $\mathrm{aOR}$ & $95 \% \mathrm{Cl}$ & $P$ value \\
\hline \multicolumn{13}{|c|}{ Extent of disclosure (Ref=never disclosed) } \\
\hline One group & 1.03 & 0.57 to 1.85 & 0.935 & 1.28 & 0.80 to 2.05 & 0.303 & 1.36 & 0.94 to 1.97 & 0.101 & 1.08 & 0.69 to 1.69 & 0.737 \\
\hline Two groups & 1.71 & 0.84 to 3.48 & 0.141 & 1.88 & 1.05 to 3.37 & 0.033 & 1.39 & 0.90 to 2.14 & 0.135 & 1.59 & 0.96 to 2.62 & 0.070 \\
\hline Three groups & 1.77 & 0.80 to 3.91 & 0.158 & 3.32 & 1.76 to 6.24 & $<0.001$ & 2.73 & 1.74 to 4.29 & $<0.001$ & 1.89 & 1.15 to 3.10 & 0.012 \\
\hline Four groups & 3.82 & 1.55 to 9.44 & 0.004 & 4.63 & 2.09 to 10.25 & $<0.001$ & 2.17 & 1.36 to 3.45 & 0.001 & 2.33 & 1.41 to 3.85 & 0.001 \\
\hline
\end{tabular}

All models adjusted for age, educational attainment and residence status.

*Multinomial logistic regression; reference outcome category=never tested for HIV. †Binary logistic regression; reference outcome category=nonregular testers for HIV. ¥Binary logistic regression; reference outcome category=nonregular testers for other STIs. STI, sexually transmitted infection; aOR, adjusted OR.

may be more pronounced in the present setting, where voluntary HIV testing is costly and may not be as accessible to those who are younger, and of lower socioeconomic status. However, this might also be confounded by a greater awareness or knowledge of HIV as a result of higher educational attainment. ${ }^{21-23}$ Furthermore, we found that nonresidents were more likely than Singapore residents to have had a recent HIV test and had tested more frequently for HIV and other STIs. This finding is expected as all nonresident workers and students need to be HIV negative to work or study in Singapore and may be more inclined to test voluntarily for HIV prior to their statutory medical check-ups.

Regarding disclosure of one's sexual orientation, results indicated that those who had disclosed their sexual orientation to non-LGBTQ family members and other LGBTQ individuals were more likely to have had a recent HIV test, whereas those who had disclosed to non-LGBTQ colleagues were more likely to be regular testers for HIV. We hypothesise that sexual orientation disclosure to non-LGBTQ persons may be indicative of greater self-acceptance, which is, in turn, linked to higher levels of self-esteem and motivation to engage in health-seeking behaviours, a reasoning that is consistent with findings in the extant literature. ${ }^{24-26}$ The positive, dose-response relationship between the extent of sexual orientation disclosure and all HIV/STI-related testing outcomes in the sample corroborates this position. In contrast, the link between disclosing one's sexual orientation to other LGBTQ individuals and recent HIV testing might be attributed instead to the channels through which sexual health promotion messages and prompts are being disseminated in the GBMSM community. Thus, being 'out' and more connected with other LGBTQ individuals may lead to greater exposure to HIV prevention messaging, or engagement in community-based NGO outreach programme that provide free anonymous HIV testing within the community. A separate, supplementary analysis on the associations between respondents' sociodemographic attributes and sexual orientation disclosure (online supplementary table S2) found that, in general, GBMSM with higher educational attainment were more likely, whereas older GBMSM were in general less likely to disclose their sexual orientation to others. We hypothesise that the former reflects the effect of greater socioeconomic resources and HIV and other STI knowledge and awareness, while the effect of age may indicate that younger birth cohorts are experiencing less stigma and social barriers to disclosing their sexual orientation to other individuals.

Finally, with regards to the location of the last voluntary test, we did not observe any clear associations with disclosure. However, those with higher educational attainment gravitated towards testing at the NGO-based anonymous test site, and to a greater degree, at overseas venues or self-test kits. The latter may reflect better knowledge of and greater access to alternative testing avenues that are more costly but provide greater privacy. This suggests that anonymity in HIV testing was something that this group still valued, in spite of having the highest levels of sexual orientation disclosure.

We are mindful of several limitations of our study. Recruitment of Grindr users, who are generally younger, and potentially more technologically savvy and more 'out' than the general GBMSM population, may have caused an overestimation of the proportion who had ever or recently tested for HIV or other STIs, as well as the proportions who had disclosed their sexual orientation to others. However, our participants were largely from the age range of GBMSM most affected by HIV in Singapore, specifically those aged $20-39$ years, ${ }^{11}$ and the factors we identified as associated with HIV and STI testing are likely also applicable even to non-app-using GBMSM in these age groups. As no monetary incentives were given for participation in this survey, our questionnaire was kept as brief as possible to improve the survey completion rate. The brevity of the survey instrument meant that additional confounders that might have affected the results from our multivariable models were left unmeasured. Disclosure to other LGBTQ individuals as a measure might be problematic as well, as having a profile on Grindr might constitute disclosure of one's sexual orientation to other LGBTQ individuals. However, we could not clarify these responses, but instead allowed respondents to subjectively determine what disclosure of sexual orientation meant to them in the context of each stipulated social group.

\section{CONCLUSIONS}

We conclude with several recommendations for policymakers. First, our study found that GBMSM who were older and had higher educational attainment were more likely to have had tested recently for HIV, and more frequently for HIV and other STIs. We thus recommend that HIV prevention efforts and testing subsidies be scaled up among young GBMSM who may experience financial barriers to testing, in spite of being more 'out' about their sexual orientation. Second, as those who had disclosed their sexual orientation to other LGBTQ individuals were more likely to have had a recent HIV test, we recommend that community-based sexual health promotion be sustained to 'prompt' nonregular testers to test more often. Third, given that app-using GBMSM are more likely to be younger, have higher educational attainment, more 'out', and are more sexually active, ${ }^{27-29}$ geosocial networking apps serve as an appropriate 
platform for sexual health promotion advertising and messaging to encourage HIV and other STI testing among young GBMSM who have borne the brunt of incident HIV cases in Singapore in recent years. Other studies have found that the use of geosocial networking apps for HIV and other STI prevention among GBMSM is both acceptable and effective. ${ }^{30} 31$ We also recommend that differentiated health promotion efforts and services be developed for GBMSM who might be older, have lower educational attainment and are less 'out' with their sexual orientation.

Finally, we also found that the extent of sexual orientation disclosure exhibited a positive, dose-response relationship with testing for HIV and other STIs, thus providing strong evidence for the negative impact of stigma on sexual healthseeking behaviours among GBMSM. At the individual level, we recommend the development of early intervention programmes targeted at younger GBMSM to mitigate issues of stigma and discrimination that may serve as barriers to HIV/STI testing. At the organisational level, we also recommend the scaling up of anonymous testing services among primary healthcare providers to decentralise such services, and so that individuals may test for HIV or other STIs without the fear of being identified as sexually deviant, or as GBMSM. Finally, at the policy level, we recommend that policymakers review policies and laws, such as Section 377 A of the Singapore penal code, that may reproduce stigma towards GBMSM and deter individuals from disclosing their sexual orientation, and thus the consequent utilisation of sexual health services.

\section{Handling editor Adam Huw Bourne}

Acknowledgements The study team would like to thank all the participants who took part in the study. We would like to extend our sincerest thanks to Jack HarrisonQuintana and his colleagues at Grindr for Equality for making this study possible.

Contributors RKJT, AKJT, NK, JH-Q, MI-CC and CSW contributed to the survey design, oversight of recruitment, and data collection. RKJT, AKJT and MI-CC cleaned and analysed the data. RKJT and AKJT wrote the paper. RKJT, AKJT, NK, JH-Q, MI-CC and CSW reviewed the paper.

Funding This publication is funded by the National Centre for Infectious Diseases, Singapore

Competing interests None declared.

Patient consent for publication Not required.

Ethics approval Ethics approval was obtained from the institutional review board at the National University of Singapore (NUS-IRB Reference Code S-17-335) prior to data collection.

Provenance and peer review Not commissioned; externally peer reviewed.

Open access This is an open access article distributed in accordance with the Creative Commons Attribution Non Commercial (CC BY-NC 4.0) license, which permits others to distribute, remix, adapt, build upon this work non-commercially, and license their derivative works on different terms, provided the original work is properly cited, appropriate credit is given, any changes made indicated, and the use is non-commercial. See: http://creativecommons.org/licenses/by-nc/4.0/.

\section{REFERENCES}

1 Beyrer C, Baral SD, van Griensven F, et al. Global epidemiology of HIV infection in men who have sex with men. Lancet 2012;380:367-77.

2 Marks G, Crepaz N, Janssen RS. Estimating sexual transmission of HIV from persons aware and unaware that they are infected with the virus in the USA. AIDS 2006:20:1447-50.

3 Dokubo EK, Shiraishi RW, Young PW, et al. Awareness of HIV status, prevention knowledge and condom use among people living with HIV in Mozambique. PLoS One 2014;9:e106760.
4 Huerga $H$, Venables E, Ben-Farhat J, et al. Higher risk sexual behaviour is associated with unawareness of HIV-positivity and lack of viral suppression - implications for Treatment as Prevention. Sci Rep 2017;7.

5 Kitahata MM, Gange SJ, Abraham AG, et al. Effect of early versus deferred antiretroviral therapy for HIV on survival. N Engl J Med 2009;360:1815-26.

6 Cohen MS, Chen YQ, McCauley M, et al. Antiretroviral therapy for the prevention of HIV-1 transmission. N Engl J Med 2016;375:830-9.

7 Noble M, Jones AM, Bowles K, et al. HIV testing among Internet-Using MSM in the United States: systematic review. AIDS Behav 2017;21:561-75.

8 Guadamuz TE, Cheung DH, Wei C, et al. Young, Online and in the dark: scaling up HIV testing among MSM in ASEAN. PLoS One 2015;10:e0126658.

9 Li R, Pan X, Ma Q, et al. Prevalence of prior HIV testing and associated factors among MSM in Zhejiang Province, China: a cross-sectional study. BMC Public Health 2016;16.

10 Pham MD, Aung PP, Paing AK, et al. Factors associated with HIV testing among young men who have sex with men in Myanmar: a cross-sectional study. J Int AIDS SOC 2017;20:e25026.

11 Ministry of Health Singapore. Update on the HIVIAIDS situation in Singapore 2017, 2018. Available: https://www.moh.gov.sg/resources-statistics/infectious-diseasestatistics/hiv-stats/update-on-the-hiv-aids-situation-in-singapore-2017-(june-2018) [Accessed 18 Sep 2018].

12 Chua L, RKJ T, Jie KW. Decriminalisation of same-sex relations and social attitudes: an empirical study of Singapore. Hong Kong Law Journal 2017;47:793-824.

13 Three additional sites for anonymous HIV testing from July 2014. 2014.

14 White Y, Sandfort T, Morgan K, et al. Family relationships and sexual orientation disclosure to family by gay and bisexual men in Jamaica. Int I Sex Health 2016:28:306-17.

15 Venetis MK, Meyerson BE, Friley LB, et al. Characterizing sexual orientation disclosure to health care providers: Lesbian, gay, and bisexual perspectives. Health Commun 2017:32:578-86

16 Badgett MVL. Employment and sexual orientation. J Gay Lesbian Soc Serv 1996:4:29-52.

17 den Daas C, Doppen M, Schmidt AJ, et al. Determinants of never having tested for HIV among MSM in the Netherlands. BMJ Open 2016:6.

18 Pachankis JE, Hatzenbuehler ML, Hickson F, et al. Hidden from health: structural stigma, sexual orientation concealment, and HIV across 38 countries in the European MSM Internet survey. AIDS 2015;29:1239-46.

19 Enlistment Act (Chapter 93). 1970.

20 Ministry of Manpower Singapore. Medical examination for foreign worker 2017. Available: http://www.mom.gov.sg/passes-and-permits/work-permit-for-foreignworker/sector-specific-rules/medical-examination

21 Wejnert $C$, Le B, Rose CE, et al. HIV infection and awareness among men who have sex with men-20 cities, United States, 2008 and 2011. PLoS One 2013;8:e76878.

22 Wagenaar BH, Sullivan PS, Stephenson R. HIV knowledge and associated factors among internet-using men who have sex with men (MSM) in South Africa and the United States. PLoS One 2012;7:e32915.

23 Pando MA, Balan I, Marone R, et al. HIV knowledge and beliefs among men who have sex with men (MSM) in Buenos Aires, Argentina. AIDS Behav 2013;17:1305-12.

24 Wagner GJ, Aunon FM, Kaplan RL, et al. A qualitative exploration of sexual risk and HIV testing behaviors among men who have sex with men in Beirut, Lebanon. PLoS One 2012; 7:e45566.

25 Whitman CN, Nadal KL. Sexual minority identities: outness and well-being among Lesbian, gay, and bisexual adults. J Gay Lesbian Ment Health 2015;19:370-96.

26 Riggle EDB, Rostosky SS, Black WW, et al. Outness, concealment, and authenticity: associations with LGB individuals' psychological distress and well-being. Psycho/ Sex Orientat Gend Divers 2017:4:54-62.

27 Bien CH, Best JM, Muessig KE, et al. Gay Apps for seeking sex partners in China: implications for MSM sexual health. AIDS Behav 2015;19:941-6.

28 Lehmiller JJ, loerger M. Social networking smartphone applications and sexual health outcomes among men who have sex with men. PLoS One 2014;9:e86603.

29 Weiss KM, Jonas KJ, Guadamuz TE. Playing and never testing: human immunodeficiency virus and sexually transmitted infection testing among App-Using MSM in Southeast Asia. Sex Transm Dis 2017:44:406-11.

30 Alarcón Gutiérrez M, Fernández Quevedo M, Martín Valle S, et al. Acceptability and effectiveness of using mobile applications to promote HIV and other STI testing among men who have sex with men in Barcelona, Spain. Sex Transm Infect 2018;94:443-8.

31 Holloway IW, Rice E, Gibbs J, et al. Acceptability of smartphone application-based HIV prevention among young men who have sex with men. AIDS Behav 2014;18:285-96. 